\title{
Accelerated Atherosclerosis in Takayasu Disease: Case-Control Study
}

\section{Ahmed Hatri ${ }^{1}$, Rachida Guermaz ${ }^{1}$, Jean-Pierre Laroche ${ }^{2}$, Said Taharboucht ${ }^{1}$, Fouzia Kessal ${ }^{1}$, Ferial Hamrour ${ }^{1}$, S. Zekri ${ }^{1}$, Amel Mameri ${ }^{1}$, Mansour Brouri ${ }^{1}$}

${ }^{1}$ Internal Medicine unit, Elbiar Hospital, Algiers, Algeria

${ }^{2}$ Angiology Unit, CHU Montpellier, France

Email: h_azzeddine@yahoo.fr

How to cite this paper: Hatri, A., Guermaz, R., Laroche, J.P., Taharboucht, S., Kessal, F., Hamrour, F., Zekri, S., Mameri, A. and Brouri, M. (2017) Accelerated Atherosclerosis in Takayasu Disease: CaseControl Study. Open Journal of Internal Medicine, 7, 12-24.

https://doi.org/10.4236/ojim.2017.71002

Received: January 4, 2017

Accepted: March 28, 2017

Published: March 31, 2017

Copyright $\odot 2017$ by authors and Scientific Research Publishing Inc. This work is licensed under the Creative Commons Attribution International License (CC BY 4.0).

http://creativecommons.org/licenses/by/4.0/

\begin{abstract}
Aim: The aim of our study was to evaluate the atherosclerosis prevalence in Takayasu's disease. Patients and Method: We analyzed prospectively in a case-control study a group of 64 patients with Takayasu disease aged 41 years [ \pm 11.94$]$, a group of 50 rhumatoide arthritis (RA) patients. All women aged 45 years $[ \pm 10.27]$ and a control group with an average age of 44 years $[ \pm 12.63]$. We performed a measurement of the intima-media thickness (IMT) in carotid level and we looked for the presence of carotid, aortic and femoral atheroma. Results: We found more plaques of atheroma in the Takayasu group; the carotid intima-media thickness was significantly higher in the Takayasu group and the RA group compared with the control group. The mean IMT of the Takayasu group was $0.91 \mathrm{~mm}[ \pm 0.368]$. It was $0.76 \mathrm{~mm} \mathrm{[} \pm 0.151]$ for the RA group. And $0.71 \mathrm{~mm}[ \pm 0.141]$ for the controls. (P: 0.000). CRP $>12 \mathrm{mg}$ was identified as the most strongly associated with the development of accelerated atherosclerosis in Takayasu's disease and RA (p: 0.002) with an odds ratio of 14.5 (IC: 95\%). Conclusion: The high prevalence of atherosclerosis discovered in Takayasu's disease is not explained by the traditional vascular risk factors. It is not also explained by the corticoids and immuno-suppression treatments. The systemic inflammation associated with parietal local inflammation, observed in Takayasu arteritis appears to be responsible of premature and accelerated atherosclerosis.
\end{abstract}

\section{Keywords}

Takayasus Disease, Atherosclerosis

\section{Introduction}

Mostly found in the Takayasus disease (TD) and other vasculitis conditions (gi- 
ganto cellular vasculitis, Leo Buerger, Behcet disease) the Atherosclerosis as such has often been wrongly considered as a differential diagnostic of these pathologies. Discovered after vascular surgeries, anatomo-pathological exam or vascular echographies, the Takayasus Disease (TD) often led in several cases to reconsider as such. Described for the first time a century ago by Takayasus and Onishi, the Takayasus disease, is part of the big stem arterial vasculitis. It is a non-specific chronic aorto-arteritis characterized by a media-adventicial inflammatory sclerosis with unknown etiology. Often misdiagnosed, it mainly affects the young women aged $20-40$.

The TD develops in 2 different stages. A systemic pre-occlusive stage characterized by an inflammatory thickness of the arterial walls with general and non specific signs. It generally starts between the 10 and 20 years of age and goes most often unnoticed. Few years later a second stage occurs called occlusive or sclerous that is characterized by ischemic events varying according to the vascular topography and also the rise of a supplementary vascular flow of [1]-[6]. However, the TD pathogeny is still unknown. It is a dysimmunitary disease acting particularly on the cellular immunity level and it occurs mostly on genetically prone subjects with unrecognized starting factors. Takayasu disease is characterized both by a chronic systemic inflammation and a local parietal vascular inflammation. It may represent in our view quite an interesting model of research in the "Atherosclerosis and inflammatory" field.

Formerly, infections and renal complications were the main known causes of mortality in patients presenting connective tissue diseases as in systemic lupus and rheumatoid arthritis. Nowadays, since prognostic improved thanks to new therapeutic tools and especially the fundamental treatment generalization, we noticed that the chronic inflammatory diseases are related to a high cardio vascular mortality consequent to an accelerated and premature Atherosclerosis [7]. Until recently, cardio vascular occurrences in Takayasu disease were interpreted to be only related to arterial parietal inflammation. The coronaritis induces an acute coronaries syndrome and the cerebral arteries occlusion are likely to be in some cases the origin of cerebral vascular accidents, venal artery inflammatory occlusion acting along with renal ischemia. We noticed in our practice the frequent occurring of clinical situations where inflammatory parietal thickening coexists with an unusual early and premature atherosclerosis in young patients of Takayasu's Arteritis. The most significant illustration being that of our youngest patient aged 14, presenting a vague and accelerated atherosclerosis on the carotid artery, on the aorta and hip artery. We were so puzzled that it led us to perform a controlled study of this great atherosclerosis prevalence in the TD and to compare it with the rheumatoid arthritis (RA) considered as a pathogenic atherosclerosis model related to the inflammation [7].

\section{Patients and Methods}

The main objective of our prospective study was to investigate the accelerated and premature atherosclerosis in Takayasu disease in regard to a controlled 
study group. The minimum sampling size in the study protocol had been calculated at 33 persons/group, however we increased that number to $n=50$ for statistical analysis hence the number below.

3 groups:

1) A Takayasu patients group presenting a Takayasu's disease according to the Ishikawa diagnostic criteria modified by Sharma $(\mathrm{n}=64)$ [2] [3].

2) A Rheumatoid Arthritis patients group presenting a rheumatoid arthritis according to validated diagnostic criteria (ACR 1987 and EULAR2010) $(n=50)$ [8].

3) A control group $(n=68)$.

We measured the intima-media carotid thickness and we looked for atheroma plaques through bi-dimensional doppler echography in the 3 arterial levels (carotid, aorta, femoral). The automated measure of the intima-media thickness (IMT) was made according to Mannheim consensus protocol [9]. The patients were lying in bed when the scansion longitudinal was operated. Once the structures identified, we searched the carotid bifurcation and we positioned the apparatus at $15 \mathrm{~mm}$ proximal towards the heart over the common carotid artery. The horizontal sweeping of the probe allows the search of the best possible image to identify the posterior layers of the walls corresponding to the Intima Media.

Interpretation:

An IMT $<0.7 \mathrm{~mm}$ (700 microns) was being considered as normal.

$0.7 \mathrm{~mm}<\mathrm{IMT}>1.5 \mathrm{~mm}$ was considered a thickened Intima Media

IMT $>1.5 \mathrm{~mm}$ was considered as a plaque [9].

The specific software included into General Electrics Echograph (VIVID 7) automatically calculates the IMT allowing to eliminate observers' variability and to produce values to $1 / 1000$ th $\mathrm{mm}$ out over 200 one centimeter point. For patients with carotids inflammatory thickening, we proceeded to ITM measure on the controlateral carotid whenever one of them was healthy. If the two carotids were affected, we looked through echography in mode B for atheroma patches over the different investigated areas (carotids-aorta-femorals). The automated IMT software was signaling an error message whenever we tried to measure an IMT on a carotid with inflammation. Indeed, in this case, the inflammatory media completely crushed the intima which rendered it no longer identifiable by the apparatus. The atheroma plaque was defined through echography with a focused thickness over $1.5 \mathrm{~mm}$ of the lining and was measured from adventice media interface to the intima light interface. The SPSS 21.0 statistic software was used to collect data and final statistic analysis including a descriptive analysis, a simple and stratified bi-varied analysis (Mantel and HaenzelKhi2, Khi2) and a multi-varied analysis: logistic decline. The cleared consent of patients participating to the study was obtained for every inclusion. The significance threshold was fixed to 0.05 . A difference is said to be significant if $P$ is $<0.05$. The difference is highly significant if $\mathrm{P}$ is in between 0.01 and 0.001 . The difference is highly significant if $\mathrm{P}<0.001$. 
Informed consent was obtained from the patients and approval by the ethic committee.

\section{Results}

1) Descriptive Analysis (Table 1)

Like presented in Table 1, the mean age of the whole population group is 43 years old $( \pm 11.93)$ (range 18 - 65).

The patients mean age for Takayasu group is 41 years old $( \pm 11.94)$ (range 18 $65)$.

The patients mean age for RA group, is 45 years old $( \pm 10.27)$ (range $23-62$ ).

The case control group's mean age is 44 years old $( \pm 12.63)$ (range $18-64)$. The cardio vascular risk is calculated for each patient according to Framingham equation. The mean CVR is $3.50 \%( \pm 03.09)$ (range $01-15)$ for Takayasu group, $4.37 \%$ for RA and $4.56 \%$ for the control group. Thus, the CVR calculated is low ( $<5 \%$ for 10 years old) without any significant differences between the 3 groups. The mean CRP for Takayasu group is $13.63 \mathrm{mg} / \mathrm{l}(06.82)$ (01 - 39). It is 13.50 $\mathrm{mg} / \mathrm{l}( \pm 18.40)(04-96)$ for RA group. It is $5.98 \mathrm{mg} / \mathrm{l}( \pm 06.91)(04.56)$ for the control group.

The difference is significant ( $p: 0.01$ ). The average course period for the disease is of 7.4 years (07.24) $(00-30)$ in the Takayasu group. It is approximately of 9.4 years $( \pm 05.41)(02-25)$ for RA group. $78 \%$ of Takayasu group received long course corticoids versus $88 \%$ for the RA group. The difference is not significant with a $\mathrm{p}=0.15$. No patient of the control group received long course corticoids. The average treatment period in Takayasu group is 1.2 year $( \pm 01.19)$ (range 00 $08)$. It is of 1.8 year $( \pm 01.28)$ (range $00-06)$ for RA group. The control group

Table 1. Descriptive analysis.

\begin{tabular}{|c|c|c|c|c|}
\hline $\begin{array}{l}\text { Groups } \\
\mathrm{N}: 182\end{array}$ & $\begin{array}{c}\text { TD } \\
\mathrm{N}: 64\end{array}$ & $\begin{array}{c}\text { RA } \\
\text { N: } 50\end{array}$ & $\begin{array}{l}\text { Control } \\
\mathrm{N}: 68\end{array}$ & $\mathrm{p}$ \\
\hline Age & $41.00 \pm 11.94$ & & $43.99 \pm 12.63$ & \\
\hline Weight & $66.20 \pm 11.71$ & $71.62 \pm 4.74$ & $76.13 \pm 13.76$ & 0.234 \\
\hline SAP & $133.02 \pm 18.71$ & $123 \pm 15.48$ & $128.12 \pm 19.80$ & 0.023 \\
\hline DAP & $72.88 \pm 10.07$ & $68.00 \pm 10.88$ & $75.94 \pm 11.40$ & 0.001 \\
\hline $\mathrm{HR}$ & $74.73 \pm 9.91$ & $73.28 \pm 9.29$ & $75.72 \pm 13.85$ & 0.877 \\
\hline BMI & $25.90 \pm 4.74$ & $27.48 \pm 4.17$ & $29.18 \pm 6.07$ & 0.342 \\
\hline $\begin{array}{c}\text { Duration of the } \\
\text { disease }\end{array}$ & $7.43 \pm 7.24$ & $9.42 \pm 5.41$ & 00 & 0.000 \\
\hline CVR & $3.53 \pm 3.09$ & $4.37 \pm 3.05$ & $4.56 \pm 3.34$ & 0.153 \\
\hline $\begin{array}{c}\text { Duration of } \\
\text { treatment }\end{array}$ & $1.2 \pm 1.19$ & $1.8 \pm 1.28$ & 00 & 0.000 \\
\hline CRP & $14.6 \pm 16.16$ & $17.10 \pm 21.50$ & $6.46 \pm 9.20$ & 0.01 \\
\hline Diam/Aorta & $14.31 \pm 6.82$ & $13.13 \pm 4.64$ & $13.80 \pm 3.84$ & 0.877 \\
\hline IMT & $0.91 \pm 0.36$ & $0.76 \pm 0.15$ & $0.71 \pm 0.14$ & 0.000 \\
\hline PLAQUES & $45 \%$ & $34 \%$ & $4 \%$ & 0.000 \\
\hline
\end{tabular}


never had long course corticoids. $5 \%$ of Takayasu group patients received immuno-suppressors versus $62 \%$ for the RA group. The difference is highly significant $\left(\mathrm{p}<10^{-3}\right)$ 87\% from Takayasu group patients presented an atherosclerosis defined by an average EIM over $0.70 \mathrm{~mm}$ and/or a patch to versus respectively $76 \%$ for RA group and $48 \%$ for witness group. The difference was highly significant with a $\mathrm{p}<10^{-3}$ (slide 1). $45 \%$ from Takayasu group presented atheroma (plaques) patches as opposed to $34 \%$ from RA group and $4 \%$ from the control group. The difference was highly significant with $\mathrm{p}<10^{-3}$ (slide 2). Occurrences of Atherome present in the 3 groups

2) Characteristics of Patients with Atherosclerosis (TD, RA \& Control)

The mean age of patients with atherosclerosis in Takayasu group was 41.9 years old $( \pm 11.758)$ versus 46 years old $( \pm 10.047)$ for RA group and 51.6 years old $( \pm 7.067)$ for the control group. The patients with atherosclerosis in Takayasu group were 10 years younger than those of the control group $\left(\mathrm{p}<10^{-3}\right)$. The patients with atherosclerosis in RA group were 6 years younger than those of the control group (p: 0.002). We did not find any significant difference between Takayasu group and RA group (P: 0.148). Within our study, 50\% of infra-clinic patients with atherosclerosis had hypertension. This HAT is more frequent in the control group with atherosclerosis than those of the Takayasu group or RA groups ( $\mathrm{p}<10$ power minus 3 ). The CVR relative to Framimgham Model was low in the 3 groups but much lower in Takayasu group with atherosclerosis (3.4\%) than in the control group with atherosclerosis (6.39\%). This difference is highly significative. The average CRP with Takayasu atherosclerosis $(14.6 \mathrm{mg} / \mathrm{l}$ $( \pm 16.162)$ and RA with atherosclerosis $(17.10 \mathrm{mg} / \mathrm{l})( \pm 21.509)$ were higher than CRP of the control group with atherosclerosis $(6.6 \mathrm{mg} / \mathrm{l})( \pm 9.207)\left(\mathrm{p}<10^{-3}\right)$. $79 \%$ of patients from the Takayasu group with atherosclerosis received a corticotherapy versus $84 \%$ from RA group with atherosclerosis. The corticoid average treatment period for the Takayasu group with atherosclerosis is 1.2 year $( \pm 1.225)$. It is of 1.9 year $( \pm 1.181)$ for the RA group with atherosclerosis.

3) Bivariate Analysis (Table 2)

Table 2 shows that the associated factors in bivariate analysis are:

- the age;

- the systolic arterial pressure;

- the corticotherapy;

- the CRP and the cardio vascular risk.

We noticed a positive correlation between atherosclerosis and:

- age;

- CRP;

- CVR;

- corticotherapy.

There was no correlation with weight, BMI, DAP, the time frame of the disease, treatment period and menopause.

\section{Multivariate Analysis (Table 3)}

The Multivariate Analysis presented in Table 3, gave us different results from 
Table 2. Bivariate analysis.

\begin{tabular}{|c|c|c|c|c|c|c|}
\hline \multicolumn{7}{|c|}{ (ANOVA à 1 facteur) } \\
\hline & $\begin{array}{l}\text { Square } \\
\text { Sum }\end{array}$ & Ddl & $\begin{array}{l}\text { Square } \\
\text { Average }\end{array}$ & $\mathrm{F}$ & Significance & $\mathrm{P}$ \\
\hline \multirow[t]{3}{*}{ Age } & Inter-group & 2423.757 & 1 & 2423.757 & 19.014 & 0.000 \\
\hline & Intra-group & $22,945.084$ & 180 & 127.473 & & \\
\hline & Total & $25,368.841$ & 181 & & & \\
\hline \multirow[t]{3}{*}{ Weight } & Inter-group & 240.584 & 1 & 240.584 & 1.427 & 0.234 \\
\hline & Intra-group & $30,338.785$ & 180 & 168.549 & & \\
\hline & Total & $30,579.370$ & 181 & & & \\
\hline \multirow[t]{3}{*}{ BMI } & Inter-group & 3.556 & 1 & 3.556 & 0.125 & 0.724 \\
\hline & Intra-group & 4625.022 & 163 & 28.374 & & \\
\hline & Total & 4628.578 & 164 & & & \\
\hline \multirow[t]{3}{*}{ SAP } & Inter-group & 2790.057 & 1 & 2790.057 & 8.413 & 0.004 \\
\hline & Intra-group & $56,044.575$ & 169 & 331.625 & & \\
\hline & Total & $58,834.632$ & 170 & & & \\
\hline \multirow[t]{3}{*}{ DAP } & Inter-group & 0.415 & 1 & 0.415 & 0.003 & 0.955 \\
\hline & Intra-group & $21,453.138$ & 168 & 127.697 & & \\
\hline & Total & $21,453.553$ & 169 & & & \\
\hline \multirow[t]{3}{*}{ Corticoids } & Inter-group & 3.123 & 1 & 3.123 & 13.279 & 0.000 \\
\hline & Intra-group & 42.328 & 180 & 0.235 & & \\
\hline & Total & 45.451 & 181 & & & \\
\hline \multirow[t]{3}{*}{ CRP } & Inter-group & 1552.972 & 1 & 1552.972 & 8.691 & 0.004 \\
\hline & Intra-group & $27,159.055$ & 152 & 178.678 & & \\
\hline & Total & $28,712.028$ & 153 & & & \\
\hline \multirow[t]{3}{*}{$\begin{array}{l}\text { Treatment } \\
\text { duration }\end{array}$} & Inter-group & 1.008 & 1 & 1.008 & 0.625 & 0.431 \\
\hline & Intra-group & 175.865 & 109 & 1.613 & & \\
\hline & Total & 176.872 & 110 & & & \\
\hline \multirow[t]{3}{*}{ CVR } & Inter-group & 118.746 & 1 & 118.746 & 12.365 & 0.001 \\
\hline & Intra-group & 1728.646 & 180 & 9.604 & & \\
\hline & Total & 1847.391 & 181 & & & \\
\hline \multirow[t]{2}{*}{$\begin{array}{l}\text { Disease } \\
\text { duration }\end{array}$} & Inter-group & 48.018 & 1 & 48.018 & 1.119 & 0.292 \\
\hline & Intra-group & 4806.156 & 112 & 42.912 & & \\
\hline
\end{tabular}

the Bi-Variate analysis.

The "multi regression" analysis leads to different results from the Bi-Variate analysis.

The verisimilitude ratio test pointed out that the explained deviation difference was statistically highly significant for the CRP and significant for the age.

However the test was not significant for SAP, CVR and corticoids. As from these data, we can say that two (2) components only were associated to our 
Table 3. Multivariate analysis.

\begin{tabular}{ccccc}
\hline $\begin{array}{c}\text { Tests of likelyhood } \\
\text { ratios }\end{array}$ & \multicolumn{3}{c}{} & \\
\hline Effect & $\begin{array}{c}\text { Model's } \\
\text { Ajustement criterias }\end{array}$ & Ratios tests & & \\
\hline & Model & Khi2 & Degrée & Significance (p) \\
\hline Age & 85.342 & 6.284 & 2 & 0.043 \\
CRP & 95.778 & 16.720 & 2 & 0.000 \\
SAP & 80.115 & 1.057 & 1 & 0.304 \\
DAP & 90.136 & 11.078 & 12 & 0.522 \\
Corticoïdes & & 1.920 & 14 & 0.19 \\
\hline
\end{tabular}

patients with atherosclerosis. It concerned the age and CRP. We made detailed analysis of age category and CRP to know exactly about the most implicated category in atherosclerosis.

\subsection{Multivariate Analysis According to CRP Classes (Table 4)}

Class 1: [0 - 6] mg/l Class 2: [7 - 12] mg/l Class 3:> $12 \mathrm{mg} / \mathrm{l}$

Table 4 shows that CRP class 3 (CRP $>12 \mathrm{mg} / \mathrm{L}$ ) was definitely the most frequent factor related to the atherosclerosis progress with p: 0.002 and odd ratio of 14.5 (IC 95\%) (2.05 - 34.18). As for the "multi-varied" analysis this factor powers down for type 1 (category) (CRP $<6 \mathrm{mg} / \mathrm{L}$ ) and type 2 (CRP 7 - 12).

The Takayasu with atherosclerosis average CRP is of $14.6 \mathrm{mg} / \mathrm{L}$ (16.162). It is of $17.10 \mathrm{mg} / \mathrm{L}$ (521.509) for CRP group with atherosclerosis and of $6.6 \mathrm{mg} / \mathrm{L}$ ((9.207) for witness (case control) group with atherosclerosis.

\subsection{Multivariate Analysis According to Age Class (Table 5)}

Class 1: [18 - 25] ans Classe 2: [25 - 50] ans Classe 3: [50 - 65] ans

As presented in Table 5, the multivariate analysis permitted to weight in the age role against the atherosclerosis progress. In fact the age is associated with atherosclerosis only in type $3(50-65)$ years old and particularly for the control group. It is non-significant for Takayasu group (p: 0.724) and RA group (p: $0.420)$.

\section{Discussion}

Many studies have demonstrated the relation between systemic inflammation and atherosclerosis. The systemic Lupus, and the rheumatic diseases are followed by a heavy cardio-vascular death rate [10] [11]. This phenomenon was particularly studied during rheumatic arthritis which seemed to be related to an increased mortality and morbidity mainly due to cardio-vascular reasons. Atheromatic lesions seemed to be more frequent with RA patients rather than classic cardio-vascular risk factors. [12] [13]. Warrington and Coll consider RA as an independent risk of CV diseases mostly when seen at the coronary level. [14]. In Park study regarding $53 \mathrm{RA}$ women patients without any prior CV conditions et 
Table 4. Multivariate analysis according to CRP classes.

\begin{tabular}{ccccc}
\hline CRP classes & Value & ddl & & P \\
\hline 1 & Khi-2 & 0.966 & 1 & 0.326 \\
& Correction for continuity & 0.585 & 1 & \\
& Rate of likelyhood & 0.977 & 1 & \\
& Khi-2 de & 0.050 & 1 & 0.823 \\
& Correction for continuity & 0.000 & 1 & \\
& Rate of likelyhood & 0.050 & 1 & 0.002 \\
& Khi-2 & 9.504 & 1 & \\
& Correction for continuity & 4.567 & 1 & \\
& Rate of likelyhood & 7.529 & 1 & \\
\hline
\end{tabular}

Table 5. Multivariate analysis according to age class.

\begin{tabular}{|c|c|c|c|c|c|c|}
\hline \multirow[t]{2}{*}{ Groups } & & \multicolumn{3}{|c|}{ Atherosclerosis } & \multirow[t]{2}{*}{ Total } & \multirow[t]{2}{*}{$\mathrm{p}$} \\
\hline & & & Yes & NO & & \\
\hline \multirow[t]{4}{*}{ Takayasu } & Age class & 1 & 5 & 1 & 6 & 0.724 \\
\hline & & 2 & 37 & 6 & 43 & \\
\hline & & 3 & 14 & 1 & 15 & \\
\hline & Total & 56 & 8 & 64 & & \\
\hline \multirow[t]{4}{*}{ RA } & Age class & 1 & 2 & 1 & 3 & 0.420 \\
\hline & & 2 & 22 & 9 & 31 & \\
\hline & & 3 & 14 & 2 & 16 & \\
\hline & Total & 38 & 12 & 50 & & \\
\hline \multirow[t]{4}{*}{ Control } & Age class & 1 & 0 & 7 & 7 & 0.002 \\
\hline & & 2 & 15 & 21 & 36 & \\
\hline & & 3 & 18 & 7 & 25 & \\
\hline & Total & 33 & 35 & 68 & & \\
\hline
\end{tabular}

53 control case of the same age, exists a significative IMT increase in the PR group [15]. Within the same study IMT increase is positively correlated to the length and evolution of the disease itself. Indeed in our everyday clinic work, we haven't noticed any correlation between the IMT increase and the number of years the disease has been settling in. There's no correlation as well between with the duration of the medical treatment. In the Kumeda work studying $138 \mathrm{RA}$ and 94 controls paired up by age sex and CV risks factors, IMT is significantly higher is the RA group [13]. Le length, the severity and the evolution of the disease are positively correlated to IMT. Alkaabi et al. also noticed an IMT increase in RA patients, but there's no correlation between the evolution period of the RA and the inflammatory syndromes [16]. Numerous studies have demonstrated the reduction of HDL-C in RA, which is an atherogenic risk factor [12] [13]. In addition, HDL-C is higher in patients in remission than in patients with active rheumatoid disease [13]. In our work we did not include patients with known dyslipidemia, or diagnosed after biological check-up, to avoid any confounding 
factor that can affect the development of atherosclerosis; al our patients had a low CV risk. Atherosclerosis seen in these conditions is said to be premature or accelerated because it occurs in relatively young subjects who do not have traditional cardiovascular risk factors. In our work, the average age of patients with atherosclerosis in the Takayasu group was $41.9[ \pm 11.758]$ versus $46[ \pm 10.047]$ for the RA group, and $51.6[ \pm 7.067]$ for the controls. Patients with atherosclerosis in the Takayasu group are 10 years younger than the controls $(\mathrm{p}<10-3)$. Patients with atherosclerosis in the RA group are 6 years younger than the witnesses. ( $\mathrm{P}$ : 0.002). There was no significant difference between the Takayasu group and the RA group. (P: 0.148)

In our study we have demonstrated the existence of a high prevalence of atherosclerosis in Takayasu disease with a significantly higher IMT compared to controls. It is relatively equivalent to atherosclerosis found in rheumatoid arthritis but much more severe and accelerated since there are many more plaques in the Takayasu group compared to the RA group. We chose to measure the IMT on the 2 common carotids since these segments can be evaluated with a certain reproducibility compared to the measurement on the femoral artery. In our work we based ourselves on the automated measurement of the IMT. This reduces inter-operator variability by three and up to four times. We took into consideration, the median IMT the highest of the 2 carotids. The measurement is made on a segment of $10 \mathrm{~mm}$ minimum corresponding to more than 200 measurement points on a GE Doppler ultrasound (Vivid 7) in mode B. For patients with inflammatory carotid thickening, IMT is measured on the contralateral carotid artery if it is healthy. If the 2 carotids are reached, B-mode ultrasound examination of the atheroma plaques on the different studied territories (TSAaorta-femoral) is sought. The automated EIM software reports an error message whenever an IMT is attempted on a carotid with inflammation, in which case the inflammatory media completely overwrites the intima, which is more recognized by the device. The atheroma plaque is defined echographically by a focused thickening of the wall measuring more than $1.5 \mathrm{~mm}$ measured from the weed media interface to the intima light interface. The three study groups: Takayasu, RA and controls were comparable, no significant differences were found in the CVR. The mean CVR in the Takayasu group is 03.50 [ \pm 03.096 ] [1 - 15]. It is 04.37 [ \pm 04.37 ] [ 1 - 11] for the RA group, and 4.56 [ \pm 03.34$]$ [ 1 - 15] for the control group. This is a low CV risk with one (P: 0.153). Takayasu's disease and RA mainly affect young subjects, the population studied in our work is young, its average age is $43.2[ \pm 11.83]$ [ 18 - 65]. Young age has allowed us to reduce the theoretical risk of vascular disease.

In this prospective case-control study, we chose to limit our observations to women only, on the one hand, because of the nature of the pathologies studied, TD and RA rarely affect men and on the other hand to avoid sex becoming a confusing factor in the study as men being more prone to atherosclerosis than women. We found no significant difference in the BMI of the different groups. The mean BMI of the Takayasu group is $24.62[ \pm 4.49$ ] [18 - 35], it is 26.36 
[ \pm 3.81$][20$ - 39] for the PR group and 28.92 [ \pm 5.26$]$ [19 - 42] for controls. Hypertension is more frequent in the Takayasu group, $34 \%$ versus $30 \%$ of the PR group and $37 \%$ of the controls the difference is significant (P: 0.022). The highest mean IMT of the 2 carotids is $0.91 \mathrm{~mm}$ [ \pm 0.37 ] [0.51 - 2.35] for the Takayasu group, it is $0.76 \mathrm{~mm}[ \pm 0.15][0.52-1.21]$ in the RA group, and $0.71 \mathrm{~mm}[ \pm 0.14]$ [0.30 - 1.14]. The difference is highly significant with $\mathrm{P}<10^{-3}$. A single study on atherosclerosis in Takayasu disease has been found in our literature search (Cochrane, Medline); E. Seyahi and Coll [17]. In a study grouping Takayasu, 45 lupus and 50 controls, at comparable cardiovascular risk, the mean IMT of the Takayasu group is $0.95 \mathrm{~mm}[ \pm 0.31]$. It is $0.58 \mathrm{~mm}[ \pm 0.10]$ in the lupus group and $0.59 \mathrm{~mm}[ \pm 0.10]$ in the control group. In our work, the presence of plaque is more important in the Takayasu group (29) $45 \%$ than in the RA group (17) $36 \%$. We did not find a significant difference in the prevalence of atherosclerosis between the group Takayasu compared to RA, and please let me point out again that we defined atherosclerosis by an IMT $>0.70 \mathrm{~mm}$ and/or the presence of a plaque. $87 \%$ of patients in the Takayasu group versus $76 \%$ in the RA group (P: $0.088)$. We found greater atherosclerosis in RA compared to controls; $76 \%$ in RA versus $48 \%$ in the control group ( $\mathrm{P}: 0.002$ ). The mean duration of Takayasu's disease is 7.4 years [ \pm 7.24$]$ [00 - 30]. It is 9.4 years [ \pm 5.41$]$ [02 - 25] for RA. The difference is significant $\left(\mathrm{p}<10^{-3}\right)$. In our work we couldn't correlate the duration of the disease with atherosclerosis ( $P: 0.209$ ). Corticosteroid therapy, the basis of treatment for Takayasu's disease and RA, has been used since the 1950s. Its role is controversial in the genesis and acceleration of atherosclerosis. Some studies show an atherogenic effect via adverse effects on blood pressure, glycemic profile, and lipid [18]. More recent studies highlight the protective effect of corticosteroids against arteries, by controlling inflammation and by inhibiting cell proliferation. [19] [20]. In our study, 78\% of patients in the Takayasu group and $88 \%$ in the RA group received long-term corticosteroids. In our study, the average CVR of the Takayasu group is $3.4[ \pm 2.795]$. It is $5.08[ \pm 3.053]$ in the RA group, and $6.39[ \pm 3.178]$ for the control group $\left(\mathrm{P}<10^{-3}\right)$. The CVR calculated according to the Framingham model is low in the 3 groups but is much lower in the Takayasu group with atherosclerosis (3.4) than in the controls with atherosclerosis (6.39). The difference is highly significant. In bivariate analysis, corticosteroid therapy was associated with the presence of atherosclerosis (P: 0.001), with an odds ratio of 3.06 (95\% CI). We did not find any association with immuno suppressors (P: 0.124). In logistic regression, in multivariate analysis, corticosteroid therapy is no longer associated with atherosclerosis. Seyahi \& Coll. [17] found no link between corticosteroid therapy and atherosclerosis in Takayasu's disease and lupus; According to him, this is due to the reduced number of patients in his study (Takayasu n: 30) (lupus: 45) (controls: 50).

In Takayasu disease we have demonstrated a positive relationship between the topographical classification of Lupi Herrera and the presence of atherosclerosis. Atherosclerosis, and in particular the presence of plaque, involves much more the patients of Takayasu type I (involvement of the butt of the aorta), this cer- 
tainly emphasizes the role of inflammation. The same result is found in the study by Seyahi, et al. [17].

It is now established that CRP is an independent CV risk factor in the general population [21] [22]. It is correlated with CV risk in the developing stages of rheumatoid arthritis and in the course of RA. It is also correlated with the degree of preclinical atherosclerosis, evaluated by the measurement of carotid intima-media thickness or by arterial stiffness in RA [16]. Conversely, the recurrence of coronary events and the progression of coronary atheroma measured by ultrasound is less when there is both a decrease in LDL cholesterol and CRP. CRP hepatic production is partly induced by IL-6. In our study, the average CRP of the Takayasu group is 13.63 [ \pm 6.82 ] [ 1 - 39], it is 13.50 [ \pm 18.40$]$ [ $4-96]$ in RA and $5.98[ \pm 6.91][4-56]$ in the control group. The difference is significant between the 3 groups (p: 0.01). 67\% of patients in the Takayasu group are in an inflammatory phase with CRP $>6.80 \%$ of patients in the RA group are in an inflammatory phase. In bivariate analysis, CRP is strongly associated with atherosclerosis in our work. It is the most clearly linked to atherosclerosis. This is confirmed in the multivariate analysis which found an odds ratio of 14.5 for the class of CRP > to 12 .

In our study the bivariate analysis showed that age, SAP, corticosteroid therapy, CRP and CVR are associated with atherosclerosis. Only age and CRP remained significant in multivariate analysis. CRP $>12$ was identified as the most strongly associated with the development of accelerated atherosclerosis in $\mathrm{Ta}$ kayasu's disease and RA. (P: 0.002). Odds ratio of 14.5 (CI: 95\%) This marker is associated either with an elevation of the IMT or with the presence of an atheroma plaque whatever the group (Takayasu, RA, and controls). Age remains associated with atherosclerosis in the control group for the age group $50-65$ (P: 0.002). Age is not associated with atherosclerosis of Takayasu's disease ( $P: 0.724)$ and RA (P: 0.420).

\section{Conclusion}

The high prevalence of atherosclerosis discovered in Takayasu disease and in the RA as related to witness population is not definite by the traditional vascular risk factors. It is not also specified by the corticoids and immuno-suppression. The disease length, the patient age and the treatment period are not associated with atherosclerosis. The inflammatory biologic CRP marker and the powerful vascular risk marker appear to be the strongest ingredient associated with atherosclerosis in our study. CRP over 12 increases the risk to develop atherosclerosis by 14.5. The systemic inflammation associated with parietal local inflammation, observed in Takayasu arteritis appears to be responsible of premature accelerated atherosclerosis. The results of our study and the literary review challenged us to adopt an active strategy for cardio vascular prevention of any Takayasu disease.

\section{References}

[1] Arnaud, L., Haroche, J., Mathian, A., Gorochov, G. and Amoura, Z. (2011) Patho- 
genesis of Takayasu's Arteritis: A 2011 Update. Autoimmunity Reviews, 11, 61-67. https://doi.org/10.1016/j.autrev.2011.08.001

[2] Lupi-Herrera, E., Sanchez-Torres, G., Marcushamer, J., Mispireta, J., Horwitz, S. and Vela, J.E. (1977) Takayasu's Arteritis: Clinical Study of 107 Cases. American Heart Journal, 93, 94-103. https://doi.org/10.1016/S0002-8703(77)80178-6

[3] Sharma, B.K., Jain, S., Suri, S. and Numano, F. (1996) Diagnostic Criteria for Takayasu Arteritis. International Journal of Cardiology, 54, S141-S147. https://doi.org/10.1016/S0167-5273(96)88783-3

[4] Brouri, M. (2009) Takayasu Disease in the Maghreb: Current Epidemiology. La Revue de Médecine Interne, 30, 253-254. https://doi.org/10.1016/j.revmed.2009.09.018

[5] Ishikawa, K. (1988) Diagnostic Approach and Proposed Criteria for the Clinical Diagnosis of Takayasu's Arteriopathy. Journal of the American College of Cardiology, 12, 964-972. https://doi.org/10.1016/0735-1097(88)90462-7

[6] Arnaud, L., Haroche, J., Piette, C. and Amoura, Z. (2010) Takayasu Arteritis: Development of a Momocentric Series of 82 Patients. La Revue de Médecine Interne, 31, 208-215. https://doi.org/10.1016/j.revmed.2009.01.011

[7] Solomon, D.H., Karlson, E.W. and Rimm, E.B. (2003) Cardiovascular Morbidity and Mortality in Women Diagnosed with Rheumatoid Arthritis. Circulation, 107, 1303-1307. https://doi.org/10.1161/01.CIR.0000054612.26458.B2

[8] Aletaha, D., Neogi, T., Silman, A.J., et al. (2010) Rheumatoid Arthritis Classification Criteria: An American College of Rheumatology/European League against Rheumatism Collaborative Initiative. Annals of the Rheumatic Diseases, 69, 1580-1588. https://doi.org/10.1136/ard.2010.138461

[9] Touboul, P.J., Hennerici, M.G., Meairs, S., Adams, H., et al. (2007) Mannheim Carotid Intima-Media Thickness Consensus (2004-2006). An Update on Behalf of the Advisory Board of the 3rd and 4th Watching the Risk Symposium 13th and 15th European Stroke Conferences, Mannheim, Germany, 2004, and Brussels, Belgium, 2006. Cerebrovascular Diseases, 23, 75-80. https://doi.org/10.1159/000097034

[10] Petri, M. (2000) Detection of Coronary Artery Disease and the Role of Traditional Risk Factors in the Hopkins lupus Cohort. Lupus, 9, 170-175.

https://doi.org/10.1191/096120300678828226

[11] Urowitz, M.B., Bookman, A.A.M., Koehler, B.E., Gordon, D.A., Smuthe, H.A. and Ogryzlo, M.A. (1976) The Bimodal Mortality Pattern of Systemic Lupus Erythematosus. American Journal of Medicine, 60, 221-225. https://doi.org/10.1016/0002-9343(76)90431-9

[12] Karsh, K.J., Balow, J.E. and Decker, J.L. (1979) Mortality in Lupus Nephritis. Arthritis \& Rheumatology, 22, 764-769. https://doi.org/10.1002/art.1780220712

[13] Kumeda, Y., Inaba, M., Goto, H., Nagata, M., Henmi, Y., Furumitsu, Y., et al. (2002) Increased Thickness of the Arterial Intima-Media Detected by 7 Ultrasonographie in Patients with Rheumatoid Arthritis. Arthritis \& Rheumatology, 46, 1489-1497. https://doi.org/10.1002/art.10269

[14] Warrington, K.J., Kent, P.D., Frye, R.L., Lymp, J.F., Kopecty, S.L., Goronzy, J.J., et al. (2005) Rheumatoid Arthritis in an Independent Risk Factor for Multi-Vessel Coronary Artery Disease: A Case Control Study. Arthritis Research \& Therapy, 7, R984-R991. https://doi.org/10.1186/ar1775

[15] Park, Y.B., Ahn, C.W., Choi, H.K., Lee, S.H., Nam, C.M. and Lee, S.K. (2002) Athrosclerosisin Rheumatoid Arthritis: Morphologic Evidence Obtained by Carotid Ultrasound. Arthritis \& Rheumatology, 46, 1714-179.

https://doi.org/10.1002/art.10359 
[16] Alkaabi, J.K., Ho, M., Levison, R., Pullar, T. and Belch, J.J.F. (2003) Rheumatoid Arthritis and Macrovascular Disease. Rheumatology, 42, 292-297. https://doi.org/10.1093/rheumatology/keg083

[17] Seyahi, E., Ugurlu, S., Cumali, R., Balci, H., Seyahi, N., Yurdakul, S. and Yazici, H. (2006) Atherosclerosis in Takayasu Arteritis. Annals of the Rheumatic Diseases, 65, 1202-1207. https://doi.org/10.1136/ard.2005.047498

[18] Jonsson, S.W., Backman, C., Johnson, O., Karp, K., Ludström, E., Sundqvist, K.G., et al. (2001) Increased Prevalence of Atherosclerosis in Patients with Medium Term 473 Rheumatoid Arthritis. Journal of Rheumatology, 28, 2597-602.

[19] Wei, L., MacDonald, T.M. and Walker, B.R. (2004) Taking Glucocorticoids by Prescription Is Associated with Subsequent Cardiovascular Disease. Annals of Internal Medicine, 141, 764-770. https://doi.org/10.7326/0003-4819-141-10-200411160-00007

[20] Del Rincon, I., O’Leary, D.H., Haas, R.W., et al. (2004) Effect of Glucocorticoids on the Arteries in Rheumatoid Arthritis. Arthritis \& Rheumatology, 50, 3813-3822. https://doi.org/10.1002/art.20661

[21] Ridker, P.M., Danielson, E., Fonseca, F., et al. (2008) Rosuvastatin to Prevent Vascular Events in Men and Women with Elevated C-Reactive Protein. New England Journal of Medicine, 359, 2195-207. https://doi.org/10.1056/NEJMoa0807646

[22] Schwedler, S.B., Amann, K., Wernicke, K., Krebs, A., Nauck, M., Wanner, C., Potempa, L.A. and Galle, J. (2005) Native C-Reactive Protein Increases Whereas Modified C-Reactive Protein Reduces Atherosclerosis in Apolipoprotein E-Knockout Mice. Circulation, 112, 1016-1023.

https://doi.org/10.1161/CIRCULATIONAHA.105.556530

Submit or recommend next manuscript to SCIRP and we will provide best service for you:

Accepting pre-submission inquiries through Email, Facebook, LinkedIn, Twitter, etc. A wide selection of journals (inclusive of 9 subjects, more than 200 journals)

Providing 24-hour high-quality service

User-friendly online submission system

Fair and swift peer-review system

Efficient typesetting and proofreading procedure

Display of the result of downloads and visits, as well as the number of cited articles

Maximum dissemination of your research work

Submit your manuscript at: http://papersubmission.scirp.org/

Or contact ojim@scirp.org 